\title{
The Science of Things: Unanswered Scientific Questions and Unquestioned Scientific Answers in Materials Research and Development
}

\author{
Robert W. Cahn
}

"If an experiment works, something has gone wrong."

"You can never tell which way the train went by looking at the tracks."

"All's well that ends."

-From a poster presenting Paul Dickson's "Murphy's Laws on Technology"

I believe Groucho Marx pointed out that the problem with prediction is that it is about the future, and we do not know the future. But if it is unprofitable to attempt to predict what will be known in the future, I see no such objection to emphasizing what is not known yet, but which ought to be known soon. Indeed, such an enterprise has two parts. That splendid scientific cartoonist, Sidney Harris, has a lovely drawing showing the doorway of an unidentified research institute, and in front are two signs pointing opposite ways. One says "UNANSWERED QUESTIONS," the other, "UNQUESTIONED ANSWERS." Sometimes, the most impressive advances come from questioning unquestioned answers.

A good example of an unquestioned answer that eventually was critically reexamined is the dogma that a new phase must form from an old one by the process of nucleation, a discontinuous process in a metastable starting phase with the involvement of sharp interfaces. That model was worked out over a period of years (from roughly 1910, starting with Einstein, via several other German physicists, to Charles Frank and David Turnbull in the 1950s). Then, at last in 1956, Mats Hillert showed that a new phase could form by a continuous process in an unstable starting phase, and John Cahn and John Hilliard, a few years later, took Hillert's notion further by working out the theory of a diffuse interface that gradually thickens as the unstable parent phase decomposes continuously into regions of diverging compositions. This completely new view has been immensely influential in modern materials science and the Cahn/Hilliard papers in particular are among the most frequently cited in our field.

Another example of an unquestioned answer was the organic chemists' dogma that a compound must have a unique, well-defined molecular weight and melting temperature, otherwise it could not really be a compound. Polymers do not fit that dogma, so for several decades chemists insisted that polymers were, in effect, stuck-together versions of small molecules. Until that conviction was overcome, polymer science could not properly advance. That unquestioned answer delayed the progress of polymer science by at least 20 years, roughly from 1910 until 1930.

The way things have been going in recent years, I would guess that the field in which the most unquestioned answers will walk the plank is the processing of materials. Modern processing can be said to have started with the invention of splatquenching in 1960 by Pol Duwez at Caltech. He wanted to find a way of enhancing effective quenching rates of alloys, with a view to examining metastable phases, and found to his surprise that quenching from the melt was far more effective than quenching a solid sheet or wire. That insight was then followed through to its logical conclusion, and entirely new states of matter-metallic glasses in particularwere discovered and studied. At about the same time at General Electric (GE), the conviction that sintered ceramics must always be opaque because of unavoidable residual pores was overthrown when the link between grain growth and pore removal came to be understood; pore-free ceramic could at last be manufactured, and unexpectedly, it was exploited for lamp envelopes. More recently, the chemistry of self-assembled materials, in which regular arrays are formed either spontaneously or by the intervention of a template, has advanced to the point where a new materials encyclopedia, now being prepared, has an editor wholly focused just on self-assembled materials. One of the more remarkable developments in selfassembly is the discovery and systematization of colloidal "crystals" made from suitably coated polymeric spheres that, against all expectations, attract each other enough to form regular assemblages. (That research started from an examination of natural opal.) Colloidal crystals made their bow just as photonics (optical circuitry) reached the stage when crystals with a periodicity similar to the wavelength of light were needed to act as a kind of diffracting filter. This demonstrates that, in some mysterious way, need and solution attract each other from distinct regions of the scientific spectrum.

Another form of processing that led to a wholly unexpected matching of need and solution, and which I suspect may prove to be an archetype of what the new century holds in store, was the exploitation of nuclear tracks created by energetic particles (fission fragments) passing through an insulating solid and revealed by etching. This was research done by Buford Price, Robert Walker, and Robert Fleischer at GE from 1961 on, and it was at first exploited for such purposes as age-dating geological and archaeological materials. Then, one day, the investigators discovered by chance that cancer researchers in New York needed an ultrafilter to remove viruses from fluid suspension. It transpired that thin plastic foils, when irradiated with fission fragments from uranium, could be etched to produce a uniform population of micronsized holes ideal for that medical application, and filters began to be manufactured commercially. Since then, with the expiry of patents, half a dozen manufacturers have created a multimillion-dollar industry for such medical filters.

Another example of a chance discovery that led to major developments was Donald Stookey's discovery, at Corning Glass, of FOTOCERAM, a light-sensitive glass that generates crystallization nuclei only when exposed to light, and can then be etched away where it has crystallized, but not where it is still glassy. Incredibly complicated arrays of holes and slits can be fabricated in glass or (by further development) in glass-ceramics by this approach. I am inclined to predict that the principle of photomachining, exploited in glass-ceramics and also by means of photoresist in the manufacture of integrated circuits, will ascend to new levels of subtlety in the years ahead.

These examples of colloidal crystals, nuclear tracks, and photomachinable glass-ceramics pinpoint one of the issues for the new century. As we have seen, problems and solutions can come togeth- 
er from distinct points of the compass. The issue is: How are such meetings to be brought about, at a time when of necessity working scientists have become ever more specialized, and their contacts, while often extensive, are bound to be limited in scope? Thirty years ago, in a little article I wrote about innovation and the uses of case histories, ${ }^{*}$ I urged the case for the industrial employment of "gatekeepers": "human catalysts who are gifted scientists but devote their energies to seeking out possible applications for scientific discoveries." It will probably work out better that way rather than by employing gifted technologists who cast about for improbable scientific solutions for identified needs. The need for gatekeepers is much greater now than it was 30 years ago: It will be necessary to offer respect and salaries to people who, by inclination, have very broad interests and who might in the past have been dismissed as dilettantes. A really effective gate-keeper would also need to be something of a technological historian who has made a special study of episodes such as those exemplified; furthermore, he or she would need to have served as an active researcher so as to have a realistic appreciation of what is possible and what is a pipe dream. Perhaps some enterprising university should think of offering a master's course for aspiring gate-keepers. But who will teach them?

Another route to novel processing methods will be the exploitation of analogy. Thus, the emerging use of computerforming of ceramic prototypes by "shooting" powder particles under computer control to make predetermined geometrical shapes has evident analogy to the mode of operation of an inkjet printer. Presumably, the idea first arose through this analogy. Generally, computer control of processing devices will become progressively more widespread. An example that is not widely familiar is the continuous annealing plant for sheet steel, in which a continuously moving sheet is passed through a succession of furnaces and quenching devices, with precise control of temperatures, times, and cooling rate-an approach pioneered in Japan and now being adopted elsewhere. A striking feature of such plants is that the compositions of the steels that are to be treated in this way have to be optimized for continuous annealing; they are generally very low in carbon and alloy content-just as the ink used in an inkjet printer has to be specially concocted to have the right viscosity, boiling point, and drying speed. In the

*Nature 225 (1970) p. 693.

In the coming century,
processing procedures,
especially when precisely
controlled by computer, will
need to be associated with
specially formulated
compositions of the
materials to be processed.

coming century, processing procedures, especially when precisely controlled by computer, will need to be associated with specially formulated compositions of the materials to be processed.

While I am on the subject of computers, a word is in order about databases. These have long been crucial aids to the materials scientist and engineer. They range from simple numerical tables of physical and chemical quantities, as originally published in the International Critical Tables of the 1930s or in the annual volumes of the "Rubber Bible" (the nickname for the Handbook of Chemistry and Physics), to elaborate tabulations of specialized data relating to narrow fields, as in the New Series of "Landolt-Börnstein" handbooks. Then we have the critically assessed and "optimized" collections of binary and ternary phase diagrams that are now available in their thousands and the various handbooks of lattice spacings and x-ray diffraction patterns, leading on to several computerized collections of crystal structures, and finally to the Materials Optimizer and its variants, important design tools developed by Michael Ashby and his collaborators. Most of these collections are newly available in electronic format, and items can be found electronically-often located in unexpected places or under unexpected headings. The development of greatly improved and speeded-up software for "data-mining" all sorts of databases will be one of the urgent tasks of the next few years. This will become all the more important with the advance of combinatorial methods in materials science. Combinatorial chemistry, the rapid screening, for a particular function, of thousands of compounds by an automated process, has recently been used by pharmacologists to speed up the search for new drugs; this process has been combined with the use of the Cambridge Crystallographic Database of organic crystal structures, seeking (by data-mining) compounds with particular bond lengths and interbond angles in the hope of achieving specified chemical actions. Attempts have just begun to do the same for functional materials: For instance, a thin-film deposit of continuously, linearly varying composition along the film can be prepared and its local composition automatically determined by a physical method, while (say) the magnetization or coercivity at a particular location is quickly determined by an automated high-resolution probe. It may well be (it has not happened yet) that data-mining of inorganic crystal-structure databases will be used to look for materials with the prospect of favorable properties, by analogy to what the pharmacologists are doing already.

Combinatorial methods have the potential to simplify the determination of isothermal sections of phase diagrams. Using new methods of computer control, a thin film can, in principle, be produced to incorporate the entire range of compositions of a ternary system, for instance, and crystal structures can be determined as a function of composition after suitable annealing. I expect to see this approach developed in the near future; then the years involved in determining a ternary diagram will be drastically shortened, especially if the combinatorial approach is linked with CALPHAD calculationsthe CALculation of PHAse Diagrams from thermochemical inputs.

CALPHAD is a well-developed form of computer simulation. Computer simulations of materials are, of course, on the way to becoming big business. Such simulations offer an alternative to combinatorial experiments to find a quick route to entirely novel materials. A striking example emerged from Morrel Cohen's calculations, a few years ago, of the likely hardness of a postulated carbon nitride, predicted to trump diamond. This work has unleashed an avalanche of experimental research over the past decade, though the postulated compound has proven remarkably evasive. There will certainly soon be other "big predictions" of that kind, with their inevitable tails of hopeful experimental searchers. Some will peter out in disappointment, others will lead to mounting excitement; it is impossible to predict either the themes of the simulations and predictions, or their outcomes. Groucho Marx strikes again!

Nothing has been said yet about polymers, the ever-burgeoning domain of materials science. The mass-consumer plastics are well established, and it is unlikely that any completely new massproduced plastic will surface; after all, there is a limit to the number of simple monomers like ethylene. High-strength polymeric fibers like Kevlar may also 
have reached their natural limits. The current excitement is in functional polymers and biopolymers.

The currently most promising feature of semiconducting polymers is lightemission, from diodes. This technology has come a long way in a very few years, and the initial roadblock (the insolubility in normal solvents of the key polymers) has been ingeniously circumvented. The challenge for the near future is to deposit the light-emitting devices on a flexible polymeric substrate and to develop such an assembly into a color-controlled flat screen, that is, one that can function as a full-color display. When-rather than ifthis development is perfected, the economics of television and computers will undergo a massive shift. Polymers have long had a vital role in the manufacture of integrated circuits in the form of photoresist, the photosensitive material that allows a chip to be differentially etched after exposure to light through a mask. It is a large question, subject to the Groucho Marx law, whether eventually polymers will form part of the device structure itself on a chip, and if so, whether as part of a photonic chip or as straightforward semiconducting or capacitative microdevices.

Biopolymers is a completely distinct field of advance. A range of such polymers has been developed to be progressively degradable in the body for such uses as absorbable sutures, and another range of polymers is used for controlled drug delivery. Anticancer drugs particularly tread a fine path between being ineffective (too small a dosage) and toxic (too large); closely controlled and progressive delivery from degradable polymers is an answer. Synthetic body parts (blood vessels in particular) and some kinds of artificial heart valves depend on advances in polymer science. This field will become increasingly important to medicine in the new century.

I have given the impression that massconsumer plastics may have reached a plateau in technology, if not in production volume. This is not to say that there are no corners that require the technologist's intervention. For years past, as a devoted theatergoer and world traveler, I have had two pet grouses. People who eat chocolates from an individually wrapped box are unable to disengage their delicious morsels without producing a loud, penetrating crackling sound, and the plastic bags containing pretzels and other edibles that air travelers have to open are virtually untearable. The invention of silent chocolate wraps and readily openable plastic bags would be two ways of reducing consumers' blood pressure.
While I am considering modest issues of importance to the ordinary public, I have another concern. In the developed world, wherever one travels one is subjected to a blast of pop music. I cannot find a pop-free hairdresser in my hometown, and only the most expensive restaurants protect their customers' ears from noisy and rubbishy music. Could not a consortium of electronic specialists working with biomaterials experts and clinicians find a way of injecting pop music directly into ear implants for those people who crave this kind of "fix," while preserving a blessed silence for the rest of us?

I predict, with limited
confidence, that one
development in the new
century will be some sort of
breakthrough in the uses of
ultrapure metals, and this
will then be linked to the
uses of novel dopants in
small quantities to produce
properties that we cannot
yet foresee.

Some fields that have been thoroughly examined in the recent past and seem to be "mature" may yet turn out to have a second incarnation in the new centuryunquestioned answers revisited. I am thinking particularly of ultrapurity and extreme structural perfection. Ultrapurity entered materials science through the invention of zone refining around 1950. For a decade or so, it was a crucial part of the manufacture of $\mathrm{Ge}$ and $\mathrm{Si}$ transistors until purely chemical methods of making ultrapure semiconductors rendered zone refining obsolete. Ultrapurification was the precondition of the effective use of dopants in semiconducting devices: One has to remove everything before one can usefully add something. A resolute attempt was then made to exploit zonerefining for metals as distinct from semiconductors, but the only major application proved to be the production of gas-free copper for the manufacture of vacuum circuit breakers. Nevertheless, a group of enthusiasts has continued to do research on ultrapure metals, and there have been a steady series of conferences in Japan on such metals. It is also striking that alloys such as high-grade steels have developed in the direction of progressively lower alloying contents. I predict, with limited confidence, that one development in the new century will be some sort of breakthrough in the uses of ultrapure metals, and this will then be linked to the uses of novel dopants in small quantities to produce properties that we cannot yet foresee. These might prove to be industrially important; after all, pure tungsten doped with trace quantities of three additives has been steadfastly used for a century to make filaments for ordinary electric lamps. Extreme purity has recently played a major role in communications: To make silica optical waveguides (i.e., fibers) ultratransparent, it has proven necessary to purify the core material to an extraordinary degree. Purity, quite simply, spells transparency. Just this year, a U.S. team has found that moisture originating from a hydrogen/oxygen torch and diffusing into the fiber damages transparency.

In the early days of composite materials, 40 years ago, there was a brief flurry of enthusiasm for metal whiskers, which are tiny monocrystal filaments grown from the vapor. These are structurally perfect-or at most are threaded by a single axial dislocation. Guy Suits of GE pointed out in 1965 that iron whiskers do not rust, unlike any ordinary form of iron. At about the same time, French chemists found that zone-refined polycrystalline iron oxidizes in a more regular way than impure iron. The memory of these chance findings leads me to wonder whether our successors may, one day, find a way to make very pure, very perfect coatings that can protect metal objects against corrosion.

None of the developments I have adumbrated will be easy and all will be accompanied by infuriating and seemingly terminal obstacles. Two thousand years ago, Virgil had a line in his Aeneid: "Sunt lacrimae rerum," or "There are tears inherent in things"; more loosely translated, "Murphy's Law operates always." But elsewhere, in his Georgics, Virgil had another line: "Felix qui potuit rerum cognoscere causas," "Happy is he [she] who has been able to understand the causes of things." Understanding is the key to overcoming Murphy's Law (perhaps we should call it Virgil's Valedictory). That is a truth, valid in the 20th century, that will remain equally valid in our new century. The search for understanding is what will keep us going.

If the great early heroes of our subject, such as Daniel Hanson, Robert Mehl, Gustav Tammann, Walter Rosenhain, even William Hume-Rothery, could come back to read what I have summarized here, they would reckon a good deal of it to be couched in a foreign language because our science has advanced so rapidly and pro- 
foundly in recent decades. And if I could come back myself in 100 years' time, I would surely also find a similar essay in MRS Bulletin in 2100 to be expressed in another foreign language. That is how it has to be if the search for understanding is maintained by those who follow us.

FOR Further REAding: To pursue the hares I have raised, the reader may wish to look at some of the following recent sources: R.L. Fleischer, Tracks to Innovation (Springer, New York, 1998); S.D. Stookey, Journey to the Center of the Crystal Ball (2d ed., American Ceramic Society, Westerville, Ohio, 2000); C.L. Briant, Impurities in Engineering Materials: Impact, Reliability and Control (Marcel Dekker, New York, 1999); J.B. Wachtman Jr., Ceramic Innovations (American Ceramic Society, Westerville, Ohio, 1999); L.G. Griffith, "Polymeric Biomaterials," Acta Mater. 48 (2000) p. 263; G. Wegner,
"Functional Polymers," ibid, p. 253; and P. Bartlett, R. Ottewill, and P.N. Pusey, "Superlattice Formation in Binary Mixtures of Hard-Sphere Colloids," Phys. Rev. Lett. 68 (1992) p. 3801.

Robert W. Cahn received his BSc degree in metallurgy from Cambridge University in 1945; research for his PhD degree (1950) was done in the Cavendish Laboratory (he discovered the phenomenon of polygonization, the first experimental proof that dislocations exist), and his Cambridge ScD degree was awarded in 1963. He worked on twinning in metallic uranium at the Harwell Laboratory in England, and then moved to the university world, culminating in 17 years at Sussex University (1965-1981), where he founded the first British degree course in materials science. His personal research has been in various aspects of physical metallurgy, and in 1965 he also brought out the first edition of a major multiauthor text entitled Physical Metallurgy; the last, fourth edition appeared in 1996. After a brief, quixotic experiment (1981-983) in running a French university department of metallurgy, he took refuge at his alma mater, Cambridge, where he is now a distinguished research Fellow. There, he has kept his research going and has also edited (under the $\mathrm{VCH}$ imprint) a major series of 25 multiauthor volumes that cover virtually the whole of materials science and technology. Currently, he is joint editor-in-chief of a forthcoming Pergamon encyclopedia of materials. Since 1967, he has been a materials-science correspondent for Nature, publishing around 100 essays on a great variety of materials-science themes, some of which appeared in book form in 1992. He also founded and for a time edited a number of journals, including the Journal of Nuclear Materials and the Journal of Materials Science; he is still involved in editing Intermetallics, which he founded in 1993. He is a Fellow of the Royal Society of London and of five other academies around the world.

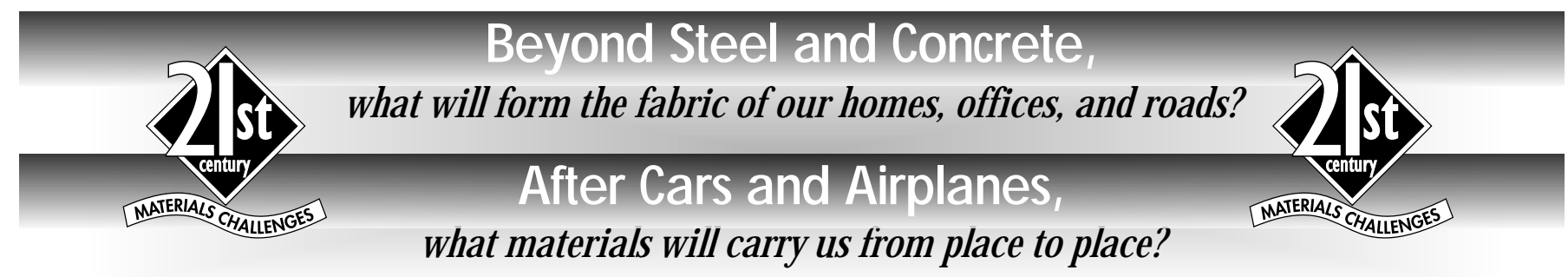

What do you see as future challenges in materials research? Send your ideas in the form of Letters to the Editor. See page 3 for details. 